\title{
EL POTENCIAL DESARROLLO DEL NUEVO PROCEDIMIENTO CONSULTIVO ANTE EL TRIBUNAL EUROPEO DE DERECHOS HUMANOS: FORTALEZAS, DEBILIDADES, OPORTUNIDADES Y AMENAZAS
}

\author{
Yaelle CACHO SÁNCHEZ*
}

SUMARIO: 1. INTRODUCCIÓN.-2. EL PROTOCOLO NÚM. 16 AL CONVENIO EUROPEO DE DERECHOS HUMANOS EN EL CONTEXTO DEL PROCESO DE REFORMA.-2.1. El principio de subsidiariedad.-2.2. El derecho de recurso individual ante el TEDH.-3. EL NUEVO PROCEDIMIENTO CONSULTIVO DEL TEDH.-3.1. Un procedimiento de reenvío judicial.-3.2. Un procedimiento en el marco de la función consultiva.-4. CONCLUSIONES.

\section{INTRODUCCIÓN}

1. El 1 de agosto de 2018, casi cinco años después de su adopción, entró en vigor el Protocolo núm. 16 al Convenio Europeo de Derechos Humanos $(\mathrm{CEDH})$ para los diez Estados miembros del Consejo de Europa que lo habían ratificado. En la actualidad, 13 de sus 47 Estados miembros son Parte en este Protocolo ${ }^{1}$. Sin embargo, la mayoría ni siquiera lo ha firmado ${ }^{2}$. Estados

* Profesora Contratada Doctora de Derecho internacional público y Relaciones Internacionales en la Universidad de Cantabria (yaelle.cacho@unican.es). Este trabajo se realiza en el marco del Proyecto "European Union in the World: International Law and Politics», Erasmus + Programme-Jean Monnet Activities, Ref. 587791-EPP-1-2017-1-ES-EPPJMO-MODULE. Todas las páginas web de referencia han sido consultadas por última vez el 30 de mayo de 2019.

1 Protocole $n^{\circ} 16$ à la Convention de sauvegarde des Droits de l'Homme et des Libertés fondamentales, de 2 de octubre de 2013 (art. 8). Los diez Estados que ratificaron inicialmente este Protocolo son: Albania, Armenia, Estonia, Finlandia, Francia, Georgia, Lituania, San Marino, Eslovenia y Ucrania. Recientemente, ha sido también ratificado por los Países Bajos, Grecia y Andorra, para quienes entrará en vigor, respectivamente, el 1 de junio, el 1 de agosto y el 1 de septiembre de 2019 (datos disponibles en https://www.coe.int/fr/web/conventions/full-list/-/conventions/treaty/214).

2 Por el momento, 25 de los 47 Estados miembros del Consejo de Europa (entre los que se encuentra España) ni siquiera han firmado este Protocolo. Otros nueve lo habrían firmado, pero todavía no ratificado, a pesar de que algunas de estas firmas datan de 2013 y 2014 (véase nota 1). Aunque este Protocolo también está abierto a la firma y ratificación de la Unión Europea (UE), no nos ocuparemos de esta posibilidad en ningún momento de nuestro trabajo, en la medida en que el Dictamen 2/13 del 
como Reino Unido han alegado que prefieren esperar a ver cómo se concreta su aplicación en la práctica ${ }^{3}$. Esta actitud es, en parte, comprensible, si consideramos que, como ha afirmado algún autor entusiasta, este Protocolo introduce "une véritable "révolution" dans le système de contrôle de la CEDH" ${ }^{4}$, al instaurar la posibilidad para las más altas jurisdicciones nacionales de los Estados parte en el mismo de solicitar opiniones consultivas al Tribunal Europeo de Derechos Humanos (TEDH) sobre cuestiones de principio relativas a la interpretación o a la aplicación de los derechos y libertades definidos por el CEDH o sus Protocolos.

2. Cierto es que el TEDH ya gozaba de una competencia consultiva junto a su función contenciosa. Sin embargo, fue definida en términos muy restringidos en el momento de ser incorporada al sistema del CEDH por el Protocolo núm. $2(1963)^{5}$. Solo podía solicitarla el Comité de Ministros respecto de cuestiones jurídicas relativas a la interpretación del Convenio y de sus Protocolos. Se pretendía evitar toda confusión posible entre la «nueva» competencia consultiva del Tribunal y su tradicional competencia contenciosa, con el fin de privilegiar esta última para que siguiera siendo el principal pilar del sistema de garantía del Convenio, en un momento en que todavía no había conocido de ningún litigio ${ }^{6}$. Una definición tan restrictiva, que se mantiene en su actual regulación en los arts. 47-49 del CEDH, ha generado solo dos pronunciamientos del $\mathrm{TEDH}^{7}$, justificando que se la haya considerado una competencia «virtual» 0 «residual» ${ }^{8}$.

3. Por otro lado, también es verdad que el Protocolo núm. 16 tampoco supone la primera vez que se plantea la extensión de la función con-

Tribunal de Justicia de la UE (TJUE) ha «tocado de muerte» la posible adhesión de esta organización al sistema del CEDH.

${ }^{3}$ La Declaración del Ministerio de Justicia británico se produjo en los siguientes términos: «The Government will therefore neither sign nor ratify Protocol 16 at this time. It will instead observe how the system operates in practice, having regard particularly to the effect on the workload of the Court, and to how the Court approaches the giving of opinions» (disponible en https://publications.parliament.uk/pa/ ld201415/ldhansrd/text/141028-wms0001.htm).

${ }^{4}$ SzYmczaK, D., «L'institutionnalisation du dialogue des juges: un nouvel espoir pour une vraie subsidiarité?», Journal d'Actualité des Droits Européens, 2013 (disponible en https://revue-jade.eu/article/ view/406).

${ }^{5}$ El Protocolo núm. 11 (1994) la incorporó al cuerpo del Convenio, sin grandes modificaciones.

${ }^{6}$ Rapport sur l'extension de la compétence de la Cour européenne des droits de l'homme en ce qui concerne l'interprétation de la Convention de droits de l'homme, Doc. 1061, de 24 de noviembre de 1959. Véanse también SzymczaK, D., «La compétence consultative de la Cour européenne des droits de l'Homme», en ONDOUA, A. y SZYMCZAK, D. (dirs.), La fonction consultative des juridictions internationales, París, Pedone, 2009, pp. 89-104, esp. p. 93, y Drzemczewski, A. Z., «Protocole nº 2», en PetTiтi, L. E., Decaux, E. e Imbert, P.-H. (dirs.), La Convention européenne des droits de l'Homme. Commentaire article par article, París, Economica, 1999, pp. 1027-1036, esp. p. 1028.

${ }_{7}$ Cour EDH, Avis consultatif sur certaines questions juridiques relatives aux listes de candidats présentées en vue de l'élection des juges de la Cour européenne des droits de l'homme (GS), de 12 de febrero de 2008, y Cour EDH, Avis consultatif sur certaines questions juridiques relatives aux listes de candidats présentées en vue de l'élection des juges de la Cour européenne des droits de l'homme (no $\left.n^{\circ}\right)$ (GS), de 22 de enero de 2010. En una ocasión anterior, el TEDH rechazó la consulta del Comité de Ministros [Cour EDH, Décision sur la compétence de la Cour pour rendre un avis consultatif (GS), de 2 de junio de 2004].

8 Ondoua, A. y SzymczaK, D. (dirs.), op. cit., nota 6. 
sultiva del TEDH más allá de los estrechos márgenes de los arts. 47-49 del $\mathrm{CEDH}^{9}$, ni siquiera resulta innovadora la propuesta de legitimar a los tribunales nacionales para consultar al Tribunal ${ }^{10}$. No obstante, fue con el Informe del Grupo de Sabios de 2006 cuando el nuevo procedimiento consultivo previsto por el Protocolo núm. 16 comenzó a adoptar su forma actual ${ }^{11}$, dando lugar a una "nouvelle manifestation de l'inventivité juridique du processus de réforme du système conventionnel de protection des droits de l'homme en Europe» ${ }^{12}$. La innovación del Protocolo núm. 16 estriba precisamente en la formulación finalmente adoptada, que no parece pueda considerarse como una mera «extensión» de su competencia consultiva ${ }^{13}$.

4. Este nuevo procedimiento consultivo centrará nuestro estudio, que, sin embargo, se aleja de un mero análisis de sus elementos definidores ${ }^{14}$. Pretendemos valorar su particular potencial en el contexto del sistema del $\mathrm{CEDH}$ para garantizar su pervivencia a futuro, en un momento en que este procedimiento ha completado su desarrollo inicial ${ }^{15} \mathrm{y}$ ha demostrado su «viabilidad» una vez aceptada y resuelta la primera solicitud de opinión consultiva $^{16}$. Desde esta perspectiva, y alejados de todo ejercicio de adivinación, nos

9 Véase, por ejemplo, el art. 29 del Convenio de Oviedo, de 4 de abril de 1997, para la protección de los derechos humanos y la dignidad del ser humano con respecto a las aplicaciones de la Biología y la Medicina.

10 Recomendación 231 (1960) de la Asamblea Consultiva del Consejo de Europa, de 22 de enero de 1960, y Doc. 1062, de 24 de noviembre de 1959. Véanse algunas propuestas doctrinales, por ejemplo, en SPIElmanN, D., "Quelques réflexions au sujet d'un recours préjudiciel éventuel devant la Cour Européenne des Droits de l'Homme», Documentação e Direito Comparado, 1987, núms. 31-32, pp. 527-546; MacDonald, R. St. J., «The Luxembourg Preliminary Ruling Procedure and Its Possible Application in Strasbourg», Mélanges en Hommage à Louis-Edmond Pettiti, Bruselas, Bruylant, 1998, pp. 593-603, y Ritleng, D., «Le renvoi préjudiciel communautaire, modèle pour une réforme du système de protection de la CEDH?», L'Europe des Libertés, 2002, núm. 7, pp. 3-7.

11 Rapport du Groupe des Sages au Comité des Ministres, 979bis Réunion, Documents CM(2006)203, de 15 de noviembre de 2006, párrs. 76-86 y 135. Para un histórico completo de las diferentes fases y órganos que han conducido a la elaboración de este Protocolo, véanse Rapport explicatif, Protocole $n^{\circ} 16$ à la Convention de sauvegarde des Droits de l'Homme et des Libertés fondamentales, párrs. 1-6 (disponible en https://rm.coe.int/CoERMPublicCommonSearchServices/DisplayDCTMContent?documentId=09 000016800d38cd), y también Dzehtsiarou, K. y O’MEara, N., "Advisory Jurisdiction and the European Court of Human Rights: A Magic Bullet for Dialogue and Docket-Control?», Legal Studies, vol. 34, 2014, núm. 3, pp. 444-468, esp. pp. 451-457.

12 Runavot, M.-C., «Le Protocole n 16 à la Convention européenne: réflexions sur une nouvelle espèce du genre», Revue générale de droit international public, vol. 118, 2014, núm. 1, pp. 71-93, esp. p. 71.

13 En este sentido, véanse, por ejemplo, Runavot, M.-C., op. cit., nota 12, p. 71, e Hinojo RoJas, M., «El Protocolo núm. 16 al Convenio Europeo de Derechos Humanos», Anuario Español de Derecho Internacional, vol. 34, 2018, pp. 675-706, esp. p. 684.

${ }_{14} \mathrm{Al}$ respecto, véanse, por ejemplo, «Part Nine - Protocol No. 16 to the Convention for the Protection of Human Rights and Fundamental Freedoms», en Schabas, W. A., The European Convention on Human Rights: A Commentary, Oxford, Oxford University Press, 2015, pp. 889-1232, y PAPROCKA, A. y ZIóŁKowsKi, M., «Advisory Opinions under Protocol No. 16 to the European Convention on Human Rights», European Constitutional Law Review, vol. 11, 2015, núm. 2, pp. 274-292.

15 Cour EDH, Règlement de la Cour, Amendements au Règlement de la Cour adoptés par la Cour plénière le 19 septembre 2016 (articles 1, 24, 29, 34, 44 et 82, nouveau chapitre X), en vigor desde el 1 de agosto de 2018, y Cour EDH, Les Lignes directrices concernant la mise en œuvre de la procédure d'avis consultatif prévue par le Protocole $n^{\circ} 16$ à la Convention, 2017.

${ }^{16}$ Cour de cassation, arrêt $\mathrm{n}^{\circ} 638$ du 5 octobre 2018 (10-19.053) (disponible en https://www.courdecassation.fr/jurisprudence_2/assemblee_pleniere_22/638_5_40365.html). La solicitud fue recibida por el 
interesa analizar los «elementos determinantes del desarrollo» de este nuevo procedimiento con el fin de identificar las fortalezas y oportunidades con las que cuenta para la consecución de sus objetivos, así como las debilidades y amenazas que acechan y que pueden incidir negativamente en la eficacia del sistema del CEDH a largo plazo. Desde esta perspectiva, resulta necesario el examen de su contexto, que no es otro que el proceso de reforma del sistema del CEDH (el «entorno» o «ambiente») (apdo. 2 del trabajo), y de sus elementos más significativos en tanto que procedimiento consultivo de reenvío judicial (la «genética» o «naturaleza») (apdo. 3 del trabajo).

\section{EL PROTOCOLO NÚM. 16 AL CONVENIO EUROPEO DE DERECHOS HUMANOS EN EL CONTEXTO DEL PROCESO DE REFORMA}

5. Comenzaremos analizando el medio específico en el que se desarrolla el Protocolo núm. 16, en tanto que «factor ambiental» que podría incidir en o condicionar el desarrollo de las capacidades y potencialidades del nuevo procedimiento. Desde esta perspectiva, el Protocolo núm. 16 es, ante todo, una de las innumerables medidas adoptadas en el proceso de reforma del sistema del CEDH iniciado en 2000 y que todavía no ha concluido. En concreto, es uno de los resultados más visibles de su segunda fase, que se conoce bajo el nombre de «Proceso de Interlaken» ${ }^{17}$, aunque comenzó con el Informe del Grupo de Sabios de 2006.

6. El mecanismo de diálogo judicial que instaura este Protocolo núm. 16, para enfrentar lo que algún autor ha tildado de talón de Aquiles del sistema del Convenio ${ }^{18}$, responde plenamente a la lógica que inspira esta segunda fase del proceso de reforma, ya que no busca tanto enfrentar a corto plazo la sobrecarga de trabajo del Tribunal para evitar el inminente colapso del sistema (como la primera fase) ${ }^{19}$, sino asegurar la pervivencia del sistema

TEDH el 16 de octubre de 2018 (núm. P16-2018-001), aceptada por el colegio de cinco jueces de la Gran Sala el 3 de diciembre de 2018 y resuelta por la Gran Sala el 10 de abril de 2019. Véanse al respecto Press Release ECHR 415 (2018), de 4 de diciembre de 2018; Press Release ECHR 132 (2019), de 10 de abril de 2019, y Cour EDH, Avis consultatif relatif à la reconnaissance en droit interne d'un lien de filiation entre un enfant né d'une gestation pour autrui pratiquée à l'étranger et la mère d'intention demandé par la Cour de cassation française (GS), de 10 de abril de 2019. En esta primera ocasión, por tanto, el TEDH ha tardado algo menos de dos meses en declarar admisible la demanda de opinión consultiva y otros cuatro meses en resolverla, lo que hace un total de seis meses.

$17 \mathrm{El}$ «Proceso de Interlaken» se ha configurado en torno a la celebración de una serie de grandes conferencias políticas, tomando su nombre de la primera que se celebró en Interlaken en 2010. Las demás se celebraron en Izmir, Brighton, Bruselas y Copenhague en 2011, 2012, 2015, 2018, respectivamente.

18 Sicilianos, L.-A., "L'élargissement de la compétence consultative de la Cour européenne des droits de l'homme. À propos du Protocole n ${ }^{\circ} 16$ à la Convention européenne des droits de l'homme», Revue trimestrielle des droits de l'homme, 2014, núm. 97, pp. 9-28, esp. p. 12.

19 Rapport explicatif, Protocole $n^{\circ} 14$ à la Convention de sauvegarde des Droits de l'Homme et des Libertés fondamentales, amendant le système de contrôle de la Convention, párrs. 7-8 y 13 (disponible en http://conventions.coe.int/Treaty/FR/Reports/Html/194). El resultado más visible de esta primera fase de la reforma (2000-2004) ha sido el Protocolo núm. 14 al CEDH, de 13 de mayo de 2004. 
del Convenio a largo plazo, trascendiendo el plano europeo. Un instrumento idóneo para la inclusión de una dimensión nacional en el marco de la reforma del sistema ha sido el principio de subsidiariedad ${ }^{20}$, a cuyo fortalecimiento también pretende responder el Protocolo núm. $16^{21}$. En cualquier caso, la forma que adoptase el nuevo procedimiento consultivo no podía menoscabar el otro gran eje sobre el que se ha hecho pivotar toda la reforma, el derecho de recurso individual ante el TEDH, que además se ha reafirmado como piedra angular del sistema de garantía colectiva del Convenio ${ }^{22}$. Nos interesa, por tanto, la confrontación del Protocolo núm. 16 con ambos parámetros como vía para identificar las oportunidades y amenazas a las que se enfrenta el nuevo procedimiento consultivo.

\subsection{El principio de subsidiariedad}

7. El vínculo entre el nuevo procedimiento consultivo y el principio de subsidiariedad, patente ya en el propio Preámbulo del Protocolo, resulta evidente por su propia naturaleza. El juez nacional, a quien, de conformidad con el principio de subsidiariedad, incumbe en primer lugar garantizar el disfrute efectivo de los derechos consagrados en el sistema y una reparación idónea ${ }^{23}$, se encontrará en mejores condiciones para ello si se le permite pedir con carácter previo una opinión al TEDH sobre un problema de interpretación o de aplicación del $\mathrm{CEDH}^{24}$. Este vínculo ofrece, además, un contexto lleno de oportunidades para el desarrollo del nuevo procedimiento consultivo, dado el «cambio de paradigma» en la definición del principio de subsidiariedad que se está consolidando en el marco de la reforma del sistema del CEDH, en conexión con el afianzamiento de la naturaleza circular del sistema y la

${ }^{20}$ La reforma se hizo eco de este principio desde el primer momento (Rapport explicatif, Protocole $n^{\circ} 14$ à la Convention de sauvegarde des Droits de l'Homme et des Libertés fondamentales, amendant le système de contrôle de la Convention, párr. 12), desarrollándolo en las sucesivas Conferencias del «Proceso de Interlaken» (Déclaration d'Interlaken, párrafos dispositivos 2-3; Déclaration d'Izmir, Preámbulo, párrs. 5-6; Déclaration de Brighton, párrafos dispositivos 3-4; Déclaration de Bruxelles, Preámbulo, párr. 7, y Déclaration de Copenhague, párrs. 6-11), aunque el documento más relevante es: Cour EDH, Suivi d'Interlaken. Principe de Subsidiarité, Note du Jurisconsulte, de 8 de julio de 2010 (disponible en http://www.echr.coe.int/Documents/2010_Interlaken_Follow-up_FRA.pdf).

21 Protocolo núm. 16, Preámbulo, párr. 3.

${ }^{22}$ Rapport explicatif, Protocole $n^{\circ} 14$ à la Convention de sauvegarde des Droits de l'Homme et des Libertés fondamentales, amendant le système de contrôle de la Convention, párrs. 10-12; Déclaration d'Interlaken, párrafo dispositivo 1; Déclaration d'Izmir, Plan de Seguimiento, A; Déclaration de Brighton, párrafo dispositivo 1; Déclaration de Bruxelles, párrafo dispositivo 1, y Déclaration de Copenhague, párrafo dispositivo 1.

${ }_{23}$ Cour EDH, Suivi d'Interlaken. Principe de Subsidiarité, Note du Jurisconsulte, de 8 de julio de 2010, párr. 2. Véanse también, por ejemplo, GARcía RocA, J., «La muy discrecional doctrina del margen de apreciación nacional según el Tribunal Europeo de Derechos Humanos: soberanía e integración», UNED. Teoría y Realidad Constitucional, 2007, núm. 20, pp. 117-143, esp. p. 123, y MAHONEY, P., «Marvelous Richness of Diversity or Individual Cultural Relativism», en STEINER, H. y ALSTON, Ph. (coords.), International Human Rights in Context. Law, Politics, Morals, 2. a ed., Oxford, Oxford University Press, 2000, pp. 854 y ss.

${ }^{24}$ SZYMCZAK, D., op. cit., nota 4. 
noción de responsabilidad compartida, en tanto que corolarios del mismo, como trataremos de explicar a continuación.

8. Si bien tradicionalmente el principio de subsidiariedad se concebía como un límite a la intervención del TEDH ${ }^{25}$, se pone ahora el acento en que corresponde en primer lugar a las autoridades nacionales garantizar el disfrute efectivo de los derechos consagrados en el sistema ${ }^{26}$, por lo que están obligadas a la acción. Esta nueva concepción afecta, por tanto, fundamentalmente, al reparto de las competencias de acción y de intervención dentro del sistema, es decir, al aspecto procesal del principio, reflejándose en la nueva concepción de la regla del agotamiento de los recursos internos y en el impacto de la jurisprudencia del TEDH ${ }^{27}$. De este modo, los Estados quedan obligados a la acción desde una doble perspectiva. En primer lugar, la regla del agotamiento de los recursos internos se asienta ahora en la idea de que en los Estados parte deben existir recursos internos que pueden ser interpuestos por el demandante para la protección de sus derechos y que estos recursos son efectivos y eficaces ${ }^{28}$. El nuevo procedimiento consultivo contribuiría a la eficacia de estos recursos disponibles a nivel nacional, ya que ayudaría "à clarifier les dispositions de la Convention et la jurisprudence de la Cour et fourniraient ainsi des orientations supplémentaires permettant d'assister les États Parties à éviter de nouvelles violations» ${ }^{29}$.

9. En segundo lugar, como se viene insistiendo en el «Proceso de Interlaken», el impacto de las sentencias del TEDH no queda limitado a su obligatoriedad para los Estados contratantes en los litigios en que sean parte, sino que los demás Estados también deberían «tenir compte des développements de la jurisprudence de la Cour, notamment en vue de considérer les conséquences qui s'imposent suite à un arrêt concluant à une violation de la Convention par un autre État partie lorsque leur ordre juridique soulève le même problème de principe» ${ }^{30}$. Este "efecto erga omnes de facto» de las sentencias del Tribunal (o «doctrina de la cosa interpretada») quedaría reforzado por el Protocolo núm. 16, puesto que, como afirma su Informe Explicativo, la interpretación del Convenio y sus Protocolos contenida en las opiniones consultivas, a pesar de su carácter no vinculante (art. 5), será análoga en sus efectos a los elementos interpretativos establecidos por el Tribunal en sus sentencias y decisiones, insertándose todas ellas en su jurisprudencia ${ }^{31}$. Su valor como clarificador

25 López Guerra, L. M., «Los Protocolos de reforma núm. 15 y 16 al Convenio Europeo de Derechos Humanos», Revista Española de Derecho Europeo, 2014, núm. 49, pp. 11-29, esp. p. 15.

${ }^{26}$ Cour EDH, Suivi d'Interlaken. Principe de Subsidiarité, Note du Jurisconsulte, de 8 de julio de 2010, párr. 2 .

27 Además de este aspecto procesal, el principio de subsidiariedad integra un aspecto material (referido al reparto de competencias de decisión y de apreciación), que tiene su reflejo concreto en la doctrina de la cuarta instancia y en la doctrina del margen de apreciación. Véase al respecto Cour EDH, Suivi d'Interlaken. Principe de Subsidiarité, Note du Jurisconsulte, de 8 de julio de 2010.

${ }_{28}$ Ibid., párrs. 18-23.

29 Rapport explicatif, Protocole $n^{\circ} 16$ à la Convention de sauvegarde des Droits de l'Homme et des Libertés fondamentales, párr. 2.

${ }^{30}$ Conférence d'Interlaken, Plan d'action, apdo. 4.d).

31 Rapport explicatif, Protocole $n^{\circ} 16$ à la Convention de sauvegarde des Droits de l'Homme et des Libertés fondamentales, párr. 27. 
del Derecho haría posible su extensión a situaciones idénticas tanto para los asuntos contenciosos como consultivos, pero también a otros tribunales y órganos distintos del peticionario, con efectos incluso en Estados no parte en el Protocolo núm. 16, como sería el caso de España.

10. En definitiva, el nuevo procedimiento consultivo podría resultar un interesante instrumento para la consolidación del principio de subsidiariedad en su nueva concepción, al tiempo que este principio podría, a su vez, servir de acicate para la utilización del nuevo procedimiento por los tribunales nacionales. Esta estrecha relación (de doble vía) vendría reforzada por la «naturaleza circular» del sistema y por la noción de responsabilidad compartida, a cuya definición progresiva también ha contribuido el «Proceso de Interlaken». Por lo que a la «naturaleza circular» del sistema se refiere, comenzó a vislumbrarse con mayor claridad cuando se interiorizó que los Estados deben adoptar a nivel nacional, en el menor tiempo posible, las medidas necesarias para conformarse a las sentencias del Tribunal ${ }^{32}$ y que, poniéndose fin a las violaciones detectadas, también se impedirían nuevas violaciones semejantes, que a su vez podrían llegar a generar nuevas demandas ante el TEDH, pero que finalmente no lo harían porque encontrarían respuesta en los respectivos sistemas nacionales ${ }^{33}$. El paso siguiente fue considerar que los Estados deben ser capaces de que la protección de los derechos del Convenio quede asegurada primero en el fuero interno ${ }^{34}$. La acción preventiva por parte de los Estados se constituyó de este modo como un componente esencial de la reforma ${ }^{35}$.

11. Este componente, unido a la idea de que, a pesar de que son los Estados los actores principales de la protección de los derechos humanos, se trata de una responsabilidad compartida ${ }^{36}$, se tradujo en la identificación de diferentes líneas de actuación en la esfera preventiva, entre ellas, la necesidad de establecer una buena interacción entre los niveles nacional y europeo del sistema en el plano jurisdiccional a través de un diálogo constructivo y

32 Ripol Carulla, S., El sistema europeo de protección de los derechos humanos y el Derecho español: la incidencia de las sentencias del Tribunal Europeo de Derechos Humanos en el ordenamiento jurídico español, Barcelona, Atelier, 2007, p. 43.

${ }_{3}$ CM, Rapport des Délégués des Ministres, Assurer l'efficacité continue de la Cour européenne des Droits de l'Homme - Mise en ouvre des mesures de réforme adoptées par le Comité des Ministres lors de sa 114e Session (12 mai 2004), Document CM(2006)39-final, de 12 de mayo de 2006, apdo. I.1, y Declaración de Copenhague, párr. 11. Véanse también Salinas AlCEGA, S., El sistema europeo de protección de los derechos humanos en el siglo XXI. El proceso de reforma para asegurar su eficacia a largo plazo, Madrid, Iustel, 2009, p. 62, y La réforme du système européen des droits de l'homme. Actes du séminaire de haut niveau. Oslo, 18 octobre 2004, Estrasburgo, 2004, p. 35.

${ }^{34}$ En este sentido, véanse Morte, C., El procedimiento ante el Tribunal Europeo de Derechos Humanos y los requisitos de admisibilidad de la demanda, Valencia, Tirant lo Blanch, 2004, pp. 111 y ss.; Salinas Alcega, S., op. cit., nota 33, p. 231, y Sicilianos, L.-A., "La "réforme de la réforme" du système de protection de la Convention européenne des droits de l'homme», Annuaire français de droit international, vol. XLIX, 2003, pp. 611-640, esp. p. 614

35 Salinas Alcega, S., op. cit., nota 33, pp. 20, 27-28 y 231.

36 Déclaration de Copenhague, párr. 10. Véanse también Déclaration d'Interlaken, Preámbulo 1, párrs. 1-3; Déclaration d'Izmir, Preámbulo, párrs. 5-6; Déclaration de Brighton, párrafos dispositivos 3-4; Déclaration de Bruxelles, Preámbulo, párrafo 7, y Déclaration de Copenhague, párrs. 6-11. 
continuo ${ }^{37}$. Un importante paso hacia la formalización de este diálogo, que venía ya teniendo diferentes manifestaciones en el plano informal ${ }^{38}$, ha sido el lanzamiento en 2016 de la Red de intercambio de información sobre la jurisprudencia del CEDH con los tribunales superiores nacionales (Red de Tribunales Superiores o Superior Courts Network-SCN), aunque el mayor exponente viene representado por el procedimiento de opinión consultiva previsto por el Protocolo núm. 16. La intervención del TEDH en un estadio tan temprano, "[w] hen the case was still before a national court, would have benefits for the economy of proceeding and might, therefore, contribute towards the more effective protection of human rights in Europe» ${ }^{39}$. En todo caso, resulta llamativa la significativa acogida de la Red por parte de los Tribunales Superiores ${ }^{40}$, que contrasta con la escasa voluntad política de los Estados para ratificar el Protocolo núm. 16.

12. A pesar de las enormes potencialidades que ofrece este contexto para el desarrollo del nuevo procedimiento, la amenaza más seria que se cierne sobre él es precisamente la reticencia de algunos Estados a estos desarrollos y las críticas al TEDH que se han dejado sentir a lo largo de todo el «Proceso de Interlaken». En un intento por superar la susceptibilidad de los Estados soberanos $^{41}$, el Protocolo núm. 16 hace suyo el pragmatismo que preside la reforma incorporando una serie de características al nuevo procedimiento, que se traducen en importantes diferencias respecto de la cuestión prejudicial ante el Tribunal de Justicia de la Unión Europea (TJUE), que le sirvió de modelo. De una parte, los Estados pueden decidir, ratificando o no el Protocolo ${ }^{42}$, si permiten o no que sus altos tribunales soliciten opiniones consultivas. De otra parte, si los Estados ofrecen esta posibilidad, sus altos tribunales serán libres para decidir si formulan o no esa solicitud ${ }^{43}$. Estas diferencias no se van a traducir necesariamente en una minoración en la protección de los derechos humanos, dada la posibilidad para la víctima de acudir al TEDH, que no tiene en la cuestión prejudicial ante el TJUE ${ }^{44}$. Este carácter doblemente facultativo del Protocolo y del procedimiento ha llevado además a algún autor a augurar que no será previsible una avalancha

37 Déclaration de Copenhague, párr. 33.

38 El TEDH viene desarrollando desde hace años una intensa actividad informal de diálogo con otras instancias judiciales nacionales, e incluso internacionales, que se concreta en visitas, encuentros, reuniones, seminarios, jornadas o invitaciones a la apertura del año judicial. Véanse, a modo ejemplificativo, las acciones realizadas durante 2016 en Cour EDH, Rapport annuel 2016, pp. 6 y 9-10.

39 MacDonald, R. St. J., op. cit., nota 10, p. 603.

40 Esta iniciativa, destinada a favorecer un intercambio mutuo de información entre el TEDH y los tribunales superiores nacionales, que se lanzó en 2015 en fase de prueba con las jurisdicciones superiores francesas (Consejo de Estado y Corte de Casación), se extendió rápidamente, consiguiendo en 2017 un total de 64 jurisdicciones superiores de 34 Estados, entre ellos el Tribunal Constitucional español. Véanse Cour EDH, Rapport annuel 2016, pp. 10-11, y Cour EDH, Rapport annuel 2017, pp. 9 y $149-152$.

41 Runavot, M.-C., op. cit., nota 12, p. 87.

42 Sus arts. 6 y 8 lo configuran como un Protocolo adicional y facultativo.

${ }^{43}$ Protocolo núm. 16 (art. 1), y Rapport explicatif, Protocole $n^{\circ} 16$ à la Convention de sauvegarde des Droits de l'Homme et des Libertés fondamentales, párr. 7.

${ }^{44}$ MacDonald, R. St. J., op. cit., nota 10, pp. 601-602. 
de demandas ${ }^{45}$. Dejando de lado cualquier ejercicio adivinatorio por nuestra parte, lo que sí es cierto es que estas características del nuevo procedimiento que pretenden enfrentar el contexto poniéndolo a su favor, dejan abierta una cuestión capital como es la utilización que efectivamente se va a hacer de este nuevo procedimiento en la práctica, pudiendo llegar a provocar un uso escaso del mismo, que supondría dejarlo sin efectos. La presentación de la primera demanda de opinión consultiva en un tiempo tan breve desde la entrada en vigor del Protocolo núm. 16 y la excelente acogida de la Red de Tribunales Superiores parecen, sin embargo, ofrecer un panorama alentador de cara a los tribunales nacionales.

13. Pero estas previsiones paliativas no han logrado evitar o reducir las reticencias de los Estados ${ }^{46}$, sino que se han hecho patentes, por ejemplo, como vimos, en el marco de la prestación del consentimiento en obligarse por el Protocolo núm. $16^{47}$. No obstante, la mayor amenaza ha tomado carta de naturaleza en la propuesta británica consagrada finalmente en el art. 1 del Protocolo núm. 15, si bien es cierto que rebajando el nivel de iniciativas previas $^{48}$. La incorporación en el Preámbulo del CEDH de la doctrina del margen de apreciación junto al principio de subsidiariedad que consagrará el Protocolo núm. 15 cuando entre en vigor ${ }^{49}$, podría parecer por sí misma una reforma superflua o simbólica, ya que al fin y al cabo es bien sabido que el TEDH utiliza habitualmente ambos principios desarrollados por su jurisprudencia. No obstante, privilegiar este elemento del principio de subsidiariedad frente a los demás que lo componen, alegando razones «de transparencia y

45 Sicilianos, L.-A., op. cit., nota 18, p. 15.

46 Véanse las reticencias de Reino Unido y otros Estados en DonALD, A., "Chapter 8. The Implementation of Judgments of the European Court of Human Rights against the UK: Unravelling the Paradox», en Ziegler, K. S., Wicks, E. y Hodson, L. (eds.), The UK and European Human Rights: A Strained Relationship?, Londres, Hart, 2015, pp. 135-162; LouIs, J.-V., «La présidence britannique du Conseil de l'Europe et la Cour de Strasbourg», Ces Cahiers, 2012, p. 7; MYJER, E., "Why Much of the Criticism of the European Court of Human Rights is Unfounded», en Flogaitis, E., Zwart, T. y Fraser, J., The European Court of Human Rights and its Discontents. Turning Criticism into Strength, Cheltenham, Edward Elgar, 2013, pp. 37-54, esp. p. 41, y O'MEARA, N., "Reforming the ECtHR: The Impacts of Protocols 15 and 16 to the ECHR», iCourts Working Paper Series, 2015, núm. 31, 32 pp., pp. 5-11 y 17-22.

47 Véase nota 3.

48 Así, por ejemplo, el Proyecto de Declaración de Brighton presentado por Reino Unido proponía "that article 35 of the Convention should further be amended to make clear that an application is inadmissible if it is the same in substance as a matter that has been examined by a national court taking into account the rights guaranteed by the Convention, unless the Court considers that: i) The national court clearly erred in its interpretation or application of the Convention rights; o ii) The application raises a serious question affecting the interpretation or application of the Convention. And invites the Committee of Ministers to adopt the necessary amending instrument within one year» [Draft Brighton Declaration, párr. 23.c)].

49 Los dos Estados que todavía no han prestado su consentimiento en obligarse por este protocolo no facultativo (Protocolo núm. 15 al Convenio para la Protección de los Derechos Humanos y de las Libertades Fundamentales, de 2 de octubre de 2013, art. 1) son Italia y Bosnia Herzegovina. España lo hizo el 20 de septiembre de 2018 (véase https://www.coe.int/en/web/conventions/full-list/-/conventions/treaty/213). El CEDH únicamente contemplaba explícitamente las manifestaciones más claras de este principio estructural del Derecho internacional de los derechos humanos (principalmente en sus arts. 1, 13, 19 y 35.1), si bien sobre esta base normativa fue tempranamente reconocido por el propio Tribunal y ampliamente desarrollado por su jurisprudencia. 
accesibilidad $»^{50}$, parece más un intento de garantizar las competencias nacionales que la protección efectiva de los derechos convencionales ${ }^{51}$. De este modo, «le Protocole $n^{\circ} 15$ emporte un risque non négligeable de permettre, à l'avenir, une certaine 'instrumentalisation' du principe de subsidiarités 52 y ello a pesar de que su Informe explicativo matiza que este nuevo considerando «est destiné [...] à rester cohérent avec la doctrine de la marge d'appréciation telle que développée par la Cour dans sa jurisprudence» ${ }^{33}$. Su valor instrumental o simbólico va a depender del uso que se haga en el futuro de esta nueva previsión, por lo que esta amenaza, nada desdeñable, permanece latente, más aún si se tiene en cuenta que el Tribunal podría estar siendo receptivo a este mensaje político, en particular en algunos casos contra Reino Unido ${ }^{54}$.

\subsection{El derecho de recurso individual ante el TEDH}

14. De conformidad con el Protocolo núm. 16, el hecho de que el Tribunal haya adoptado una opinión consultiva sobre una cuestión planteada en el contexto de un asunto pendiente ante una jurisdicción de un Estado parte no impide a una parte en este asunto ejercer, posteriormente, su derecho de recurso individual en virtud del art. 34 del Convenio. Es decir, el TEDH mantiene su competencia para decidir sobre las demandas individuales presentadas por cualquiera de las partes en el litigio ante el tribunal nacional que pidió la opinión consultiva ${ }^{55}$, quedando de este modo preservado el derecho de recurso individual ante el TEDH que el «Proceso de Interlaken» ha consagrado como piedra angular del sistema, con lo que vendría a conciliar las dos visiones tradicionalmente enfrentadas sobre el papel del TEDH (limitado a proporcionar justicia individual o a asumir su papel constitucional "as the authoritative interpreter of the Convention» $)^{56}$.

50 Déclaration de Brighton, párr. 12.b).

51 Runavot, M.-C., op. cit., nota 12, p. 91. En un sentido similar: véanse Tulkens, F., «La Cour européenne des droit de l'homme et la Déclaration de Brighton. Oublier la réforme et penser l'avenir», Cahiers de droit européen, vol. 48, 2012, núm. 2, pp. 305-343, esp. p. 341; AMNISTía INTERNACIONAL, «Declaración de Brighton: Estados deben tratar con seriedad Tribunal Europeo, no cuestionar independencia», nota de prensa, de 20 de abril de 2012 (recuperado el 26 de enero de 2018 de https:// www.amnesty.org/es/press-releases/2012/04/brighton-trib-eur-no-cuestionar-independencia/), e INSTITUT DE Drets Humans de Catalunya, La nueva reforma del Tribunal Europeo de Derechos Humanos, HURI-AGE Consolider-Ingenio 2010, Agència Catalana de Cooperació al Desenvolupament, noviembre de 2012, p. 9 (recuperado el 26 de enero de 2018 de www.corteidh.or.cr/tablas/r29690.pdf).

52 SzYMcZaK, D., op. cit., nota 4.

53 Rapport explicatif du Protocole $n^{\circ} 15$ portant amendement à la Convention de sauvegarde des Droits de l'Homme et des Libertés fondamentales, párr. 7 (disponible en https://www.echr.coe.int/Documents/Protocol_15_explanatory_report_FRA.pdf). Véase LÓPEZ GUERRA, L. M., op. cit., nota 25, p. 19.

${ }^{54}$ O'Meara, N., op. cit., nota 46, pp. 19-22. La autora menciona expresamente las opiniones concordantes en tres asuntos de 2013 contra Reino Unido: Animal Defenders International, Shindler y Vinter.

${ }_{55}$ Cour EDH, Document de réflexion sur la proposition d'élargissement de la compétence consultative de la Cour, 2012, párrs. 6-7 (disponible en https://www.echr.coe.int/Documents/2013_Courts_advisory_ jurisdiction_FRA.pdf), y LÓPEZ GUERRA, L. M., op. cit., nota 25, p. 28.

56 JAHN, J., «Normative Guidance from Strasbourg through Advisory Opinions. Deprivation or Relocation of the Convention's Core?», ZaöRV, vol. 74, 2014, pp. 821-846, esp. p. 842. 
15. No obstante, el Informe explicativo del Protocolo núm. 16 precisa que, cuando una demanda (se entiende, presentada por alguna de las partes en el litigio que provocó la petición consultiva) sea depositada después de un procedimiento en el marco del que el Tribunal haya efectivamente adoptado una opinión consultiva, se espera que los elementos de la demanda referidos a las cuestiones tratadas en la opinión consultiva sean declarados inadmisibles o $\operatorname{archivados}^{57}$. La causa de inadmisibilidad relativa a que sea esencialmente la misma que una demanda examinada por el Tribunal, y no contenga hechos nuevos [art. 35.2.b) del CEDH] contribuiría a este resultado ${ }^{58}$. Entendemos que estos efectos se producirán únicamente si el tribunal nacional se hubiera conformado a la opinión consultiva, porque lo contrario supondría una seria amenaza para el derecho de recurso individual ante el TEDH, pero no se dice nada al respecto en el Informe explicativo, aunque el Tribunal se ha manifestado desde el principio en este sentido ${ }^{59}$.

16. En cambio, el Informe explicativo dispone a continuación que las opiniones consultivas no tienen ningún efecto directo sobre otras demandas posteriores ${ }^{60}$, debiendo entenderse que se refiere esta vez a las demandas presentadas por partes ajenas al litigo que dio origen al procedimiento consultivo, y que, en consecuencia, no sufrirán la misma suerte en cuanto a su admisibilidad. No obstante, el Informe explicativo añade, como vimos, que estas opiniones consultivas se insertarán en la jurisprudencia del TEDH, con efectos análogos a los elementos interpretativos establecidos por el Tribunal en sus sentencias y decisiones ${ }^{61}$. Otro elemento a valorar es que las demandas de opinión consultiva serán tramitadas con prioridad ${ }^{62}$, por lo que estas otras «demandas posteriores» podrían haber sido presentadas con anterioridad, pero tratadas posteriormente. Por tanto, si bien las opiniones consultivas no producirán efectos sobre estas demandas "posteriores» en el plano formal, sí que los tendrán en la decisión sobre el fondo. Desde esta perspectiva, se ha argumentado que se corre el riesgo de menoscabar el derecho de recurso individual en la medida en que "the opinion would prejudice the ECtHR's decision, especially of cases [...] already pending before ECrHR» ${ }^{63}$.

17. Por otro lado, este marco, puesto en relación con algunas de las reformas introducidas por el Protocolo núm. 14, podría tener efectos positivos sobre el filtrado y el tratamiento de las demandas individuales en plazos ra-

\footnotetext{
57 Rapport explicatif, Protocole $n^{\circ} 16$ à la Convention de sauvegarde des Droits de l'Homme et des Libertés fondamentales, párr. 26, leído conjuntamente con párr. 27.

58 Este resultado ya fue previsto por MACDonALD, R. St. J., op. cit., nota 10, p. 602.

59 Cour EDH, Document de réflexion sur la proposition d'élargissement de la compétence consultative de la Cour, 2012, párr. 10.

${ }^{60}$ Rapport explicatif, Protocole $n^{\circ} 16$ à la Convention de sauvegarde des Droits de l'Homme et des Libertés fondamentales, párr. 27.

${ }^{61}$ Ibid.

62 Véase TEDH, La política del TEDH con respecto a la prioridad de los asuntos, de 22 de mayo de 2017 (disponible en https://www.echr.coe.int/Documents/Priority_policy_SPA.pdf).

${ }^{63}$ Voland, T. y Shiebel, B., "Advisory Opinions of the European Court of Human Rights: Unbalancing the System of Human Rights Protection in Europe?», Human Rights Law Review, vol. 17, 2017, pp. 73-95, esp. p. 84 .
} 
zonables. Podría pensarse que el primer grupo de demandas (en particular, cuando todos sus elementos hayan sido tratados en la opinión consultiva) serían declaradas inadmisibles o archivadas por un juez único al tratarse de demandas que no requieren de un examen complementario ${ }^{64}$, mientras que las otras demandas (en tanto que respondieran a la calificación de asuntos repetitivos) serían examinadas por un Comité de tres jueces ${ }^{65}$.

Esta oportunidad para reducir la carga del trabajo del Tribunal, potenciado por el juego conjunto de las diferentes medidas adoptadas en el marco del proceso de reforma, puede, sin embargo, llegar a amenazar el sistema si se impone como objetivo en sí mismo ${ }^{66}$, pudiendo vaciar de contenido el derecho de acceso a la justicia internacional, tanto en su dimensión formal (p. ej., cuando la declaración de inadmisibilidad o de archivo se realice de manera demasiado automática), como en su dimensión material, que requiere que se provea justicia a través de la emisión de una sentencia justa, ajustada a derecho, motivada y ejecutable ${ }^{67}$. No obstante, se han establecido algunas garantías que reducirían las potencialidades de esta amenaza. Así, en caso de duda, el juez único puede remitir la demanda a un Comité de tres jueces o a una Sala para su examen complementario ${ }^{68}$. El procedimiento acelerado y simplificado ante el Comité de tres jueces también se acompaña de dos cautelas: debe existir una jurisprudencia consolidada y el pronunciamiento debe adoptarse por unanimidad ${ }^{69}$. Además, si no concurriese esta unanimidad el asunto pasaría a una Sala de siete jueces (art. 29 del CEDH), quien, en virtud

\footnotetext{
${ }^{64}$ Protocole $n^{\circ} 14$ à la Convention de sauvegarde des Droits de l'Homme et des Libertés fondamentales, amendant le système de contrôle de la Convention, párr. 67; Cour EDH, Règlement de la Cour, Amendements au Règlement de la Cour adoptés par la Cour plénière le 19 septembre 2016 (articles 1, 24, 29, 34, 44 et 82, nouveau chapitre $X$ ), en vigor desde el 1 de agosto de 2018 (art. 48.1). Se trataría de demandas que no requieran un examen complementario al concurrir una de las causas de inadmisibilidad «objetiva» del art. 35 del Convenio. Véanse Pastor Ridruejo, J. A., «El Protocolo núm. 14 a la Convención Europea de Derechos Humanos: ¿estamos ante la reforma que necesita el Tribunal?», Revista Española de Derecho Internacional, vol. LVI, 2004, núm. 1, pp. 141-150, esp. p. 144, y TeIJo García, C., «Nueva vuelta de tuerca: perspectivas de reforma del sistema judicial de Estrasburgo tras la adopción de la Declaración de Interlaken y la entrada en vigor del Protocolo núm. 14 al Convenio Europeo de Derechos Humanos», Revista de Estudios Europeos, 2010, núm. 55, p. 91.

${ }^{65}$ Véase el art. 8 del Protocolo núm. 14 al CEDH, que modificó el art. $28 \mathrm{CEDH}$. Pensando en particular en los asuntos repetitivos, atribuyó a estos comités la competencia para, por unanimidad, declarar admisible una demanda y dictar al mismo tiempo sentencia sobre el fondo (incluida la satisfacción equitativa), que será definitiva, cuando «la cuestión subyacente al caso, relativa a la interpretación o la aplicación del Convenio o de sus Protocolos, ya haya dado lugar a jurisprudencia consolidada del Tribunal».

${ }^{66}$ Dzehtsiarou, K. y O’Meara, N., op. cit., nota 11, p. 462.

${ }^{67}$ Sobre este derecho de acceso a la justicia internacional, véase, por ejemplo, AcosTa ALVARADo, P. A., Tribunal Europeo y Corte Interamericana de derechos humanos: ¿Escenarios idóneos para la garantía del derecho de acceso a la justicia internacional?, Universidad Externado de Colombia, Ebook, 2008, en particular pp. 7-8 y 14.

${ }^{68}$ Véase el art. 7 del Protocolo núm. 14 al CEDH, que inserta un nuevo art. 27 del CEDH, y Cour EDH, Règlement de la Cour, Amendements au Règlement de la Cour adoptés par la Cour plénière le 19 septembre 2016 (articles 1, 24, 29, 34, 44 et 82, nouveau chapitre X), en vigor desde el 1 de agosto de 2018 (arts. 18.A, 27.A.4, 49.1 y 52A).

${ }^{69}$ SÁnchez Patrón, J. M., «El recurso individual ante el Tribunal Europeo de Derechos Humanos: evolución y perspectiva», Revista Europea de Derechos Fundamentales, 2011, núm. 18, pp. 167-190, esp. p. 181.
} 
de lo previsto en el art. 30 del CEDH, quedaría obligada a la inhibición en favor de la Gran Sala en aquellos supuestos en que la solución dada a un caso pudiera ser contradictoria con la doctrina anterior del Tribunal ${ }^{70}$.

\section{EL NUEVO PROCEDIMIENTO CONSULTIVO DEL TEDH}

18. Tratándose de una medida de reenvío judicial, todas las miradas para su formulación se pusieron en un modelo muy contrastado de diálogo judicial entre los tribunales nacionales y una jurisdicción internacional, como es la cuestión prejudicial ante el $\mathrm{TJUE}^{71}$, pero sin confundirse con él dado que necesitaba adaptarse al contexto examinado. Por ello también se tomaron prestados elementos de otras jurisdicciones internacionales, acercándose en particular a la función consultiva de otros tribunales internacionales de protección de derechos humanos, pero sin responder tampoco totalmente a este modelo. La combinación operada genera, por tanto, un procedimiento diferente, con unas características propias.

Esto supone que, además de los «factores ambientales» que examinamos en el apartado anterior, debemos ocuparnos también de los «factores genéticos», heredados y propios, del nuevo procedimiento consultivo en tanto que definen sus capacidades potenciales, pero que también pueden llegar a limitar su desarrollo. No debe obviarse el peligro inherente al hecho de tomar prestadas las características que más éxito han tenido en un régimen concreto para los propósitos de otro ${ }^{72}$. Por tanto, su examen desde una perspectiva comparada con los modelos de origen nos va a permitir identificar mejor sus fortalezas y debilidades intrínsecas (ad intra) de cara al logro de sus objetivos y de la pervivencia del sistema del Convenio.

\subsection{Un procedimiento de reenvío judicial}

19. El nuevo procedimiento consultivo ante el TEDH se ha configurado, ante todo, como un procedimiento de reenvío judicial. Por ello, al igual que la

70 López Guerra, L. M., op. cit., nota 25, p. 28.

71 Ibid., pp. 13-14; Rapport du Groupe des Sages au Comité des Ministres, 979 bis Réunion, Documents CM(2006)203, de 15 de noviembre de 2006, párr. 80; Intervención de François Tulkens en Dialogue entre juges. Actes du séminaire 27 janvier 2012: "Comment assurer une plus grande implication des juridictions nationales dans le système de la Convention?», Estrasburgo, 2012, p. 9 (disponible en https://www.echr.coe.int/Documents/Dialogue_2012_FRA.pdf). La cuestión prejudicial está regulada en el art. 19.3.b) del Tratado de la UE (TUE) y en el art. 267 del Tratado de Funcionamiento de la UE (TFUE), aunque no es el único procedimiento de reenvío judicial internacional de características similares: véanse los arts. 32-36 del Tratado de Creación del Tribunal de Justicia de la Comunidad Andina (TCTJCA) y los arts. 121-128 del Estatuto del Tribunal de Justicia de la Comunidad Andina (ETJCA). Véase, además, una comparativa entre ambos procedimientos, por ejemplo, en CIENFUEGos MATEO, M., "Cuestiones prejudiciales en la Unión Europea y consultas prejudiciales en la Comunidad Andina: Similitudes, diferencias e influencias», Revista Electrónica de Estudios Internacionales, vol. 25, 2013, 43 pp.

72 MacDonald, R. St. J., op. cit., nota 10, pp. 596 y 603. 
cuestión prejudicial ante el TJUE, comienza a partir de la petición, por parte de un tribunal nacional, a un tribunal internacional a nivel europeo de una resolución sobre la interpretación o aplicación que debe darse a una norma de Derecho internacional (Derecho de la Unión Europea o CEDH). Ambas fórmulas exigen también que la demanda se realice en el marco de un asunto pendiente ante la jurisdicción que hace la solicitud ${ }^{73}$. Además, los tribunales nacionales pueden dirigirse al TEDH para pedirle opiniones consultivas «sobre cuestiones de principio en relación con la interpretación o aplicación de los derechos y libertades definidos en el Convenio o sus Protocolos» ${ }^{74}$, al igual que pueden solicitar al TJUE una cuestión prejudicial de interpretación ${ }^{75}$. Es más, el propio Tribunal ha apuntado que, a la hora de valorar si se trata de una cuestión de principio, podrá recurrirse a la inspiración que se obtenga a partir de la jurisprudencia del TJUE en relación con la doctrina del «point clair $^{76}$.

20. Sin embargo, prácticamente las semejanzas acaban aquí. Debe tenerse en cuenta que este nuevo procedimiento, como hemos venido viendo, también pretende responder a dos objetivos indirectos concretos, que van a tener una incidencia fundamental en las características que adquiere y que lo separan de la cuestión prejudicial ante el TJUE. Por un lado, persigue consolidar la aplicación del CEDH de conformidad con el principio de subsidiariedad, y por otro, reducir la carga de trabajo del TEDH a largo plazo, en la medida en que se entiende que, mediante este procedimiento, el Tribunal clarificará cuestiones relativas a la interpretación del Convenio en un estadio precoz, anticipándose a la introducción ante él de posibles demandas individuales que plantearían la misma cuestión ${ }^{77}$, lo que además contribuiría a evitar el surgimiento de controversias entre los tribunales internos y el europeo y superar una relación judicial basada en la confrontación ${ }^{78}$.

21. Siendo previsible este efecto positivo sobre su carga de trabajo, no debe desconocerse, sin embargo, que el Tribunal puede verse obligado a enfrentar cuestiones de orden lingüístico vinculadas con la traducción de las demandas y documentos conexos ${ }^{79} \mathrm{y}$ de las opiniones consultivas ${ }^{80}$; que, como

\footnotetext{
${ }^{73}$ Véanse Protocolo núm. 16 (art. 1.2), y Rapport explicatif, Protocole $n^{\circ} 16$ à la Convention de sauvegarde des Droits de l'Homme et des Libertés fondamentales, párr. 10.

74 Véanse el art. 1.1 del Protocolo núm. 16, y Rapport explicatif, Protocole $n^{\circ} 16$ à la Convention de sauvegarde des Droits de l'Homme et des Libertés fondamentales, párr. 9.

${ }^{75}$ Los arts. 19.3.b) del TUE y 267 del TFUE prevén también la posibilidad de plantear una cuestión prejudicial sobre la validez de los actos adoptados por las instituciones, órganos u organismos de la UE.

${ }_{76}$ Cour EDH, Reflection paper on the proposal to extend the Court advisory opinion, ref. 3853038.

77 Cour EDH, Document de réflexion sur la proposition d'élargissement de la compétence consultative de la Cour, 2012, párr. 14.

78 Ibid., párr. 6, y Voland, T. y SHiebel, B., op. cit., nota 63, p. 80.

79 De conformidad con el Informe explicativo, las demandas podrían presentarse en la «lengua nacional oficial» utilizada en el litigio interno, a pesar de la opinión contraria mostrada por el TEDH con ocasión de su análisis del proyecto de Protocolo. En aquella ocasión, el Tribunal dejó claro que esta no era una exigencia contenida en el texto del Protocolo y que, en todo caso, se oponía a que "ce soit à elle qu'il incombe de fournir les traductions des demandes et documents y afférents. Même si elle peut comprendre le raisonnement sous tendant pareille proposition, celle-ci aurait pour effet de lui imposer une
} 
vimos, el nuevo procedimiento no necesariamente evitará las demandas individuales planteadas a posteriori; o que, como advierte Linos-Alexandre Sicilianos, "en suivant ses méthodes de travail actuelles, la Grande Chambre ne peut se prononcer que sur 25 à 30 affaires par an. Si les demandes d'avis consultatifs se multiplient, la Gran Chambre risque d'être absorbée par cette nouvelle fonction ${ }^{81}$. Los retrasos en su toma de decisiones pueden, además, tener un efecto desincentivador ${ }^{82}$. Frente a estos riesgos, se ha alegado que, al no ser de carácter contradictorio, el procedimiento durará menos tiempo y consumirá menos recursos ${ }^{83}$. Lo cierto es que la primera opinión consultiva de este tipo ha sido adoptada en algo menos de seis meses desde su recepción por el Tribunal ${ }^{84}$. No obstante, este posible efecto perverso sobre la carga de trabajo del Tribunal y sus recursos ha sido precisamente una de las principales fuentes de escepticismo respecto del nuevo procedimiento, por lo que, como veremos, se han anticipado ciertas válvulas de seguridad análogas a las previstas para las demandas de reenvío a la Gran Sala en el marco del procedimiento contencioso ${ }^{85}$. El Tribunal contaría, por tanto, con una primera batería de instrumentos para responder a esta debilidad.

22. Volviendo a las importantes diferencias que separan a ambos procedimientos de reenvío judicial, no pretendemos, sin embargo, hacer un análi-

charge coûteuse de traduction», no solo en el plano económico. Sin moverse de este planteamiento, el TEDH ha precisado que la lengua empleada en el procedimiento interno deberá ser el idioma oficial del Estado parte de quien dependa la jurisdicción demandante. Ha utilizado además un importante instrumento a su disposición para paliar los efectos negativos de la previsión del Informe explicativo, incorporando en el art. 34.7 de su Reglamento la siguiente precisión: «Si la langue en question n'est pas l'une des langues officielles de la Cour, une traduction en anglais ou en français de la demande doit être déposée dans un délai qu'il appartient au président de la Cour de fixer». Véase Cour EDH, Avis de la Cour sur le projet de Protocole $n^{\circ} 16$ à la Convention élargissant la compétence de la Cour afin de lui permettre de rendre des avis consultatifs sur l'interprétation de la Convention, Doc. DD(2013)534-rev., de 6 de mayo de 2013, párr. 14; Cour EDH, Les Lignes directrices concernant la mise en ouvre de la procédure d'avis consultatif prévue par le Protocole $n^{\circ} 16$ à la Convention, 2017, párr. 18, y Cour EDH, Règlement de la Cour, Amendements au Règlement de la Cour adoptés par la Cour plénière le 19 septembre 2016 (articles 1, 24, 29, 34, 44 et 82, nouveau chapitre X), en vigor desde el 1 de agosto de 2018 (art. 34.7).

${ }^{80}$ El Informe explicativo propone una solución para los casos donde el litigio interno no pueda reanudarse hasta que la opinión consultiva no sea traducida a la lengua de este procedimiento (Rapport explicatif, Protocole $n^{\circ} 16$ à la Convention de sauvegarde des Droits de l'Homme et des Libertés fondamentales, párr. 23). El TEDH mostró en su momento sus dudas respecto de la sugerencia de que en estos casos podría cooperar con las autoridades nacionales para la elaboración de la traducción en tiempo útil. Consideró que "cela pourrait entraîner une augmentation considérable de sa charge de travail et que cela pose en réalité la question de savoir qui doit financer les traductions. Il est évident que si la responsabilité de fournir les traductions incombe à la Cour, il faut mettre à sa disposition les ressources budgétaires correspondantes" [Cour EDH, Avis de la Cour sur le projet de Protocole $n^{\circ} 16$ à la Convention élargissant la compétence de la Cour afin de lui permettre de rendre des avis consultatifs sur l'interprétation de la Convention, Doc. DD(2013)534-rev., de 6 de mayo de 2013, párr. 14].

81 Sicilianos, L.-A., op. cit., nota 18, p. 20. En un sentido similar, véanse Dzehtsiarou, K., «Advisory Opinions: More Cases for the Already Overburdened Strasbourg Court», VerfassungsBlog, de 31 de mayo de 2013 (en https://verfassungsblog.de/advisory-opinions-more-cases-for-the-already-overburdenedstrasbourg-court/), y DzEHTSIAROU, K. y O'MEARA, N., op. cit., nota 11, p. 459.

82 O'Meara, N., op. cit., nota 46, p. 27.

83 Dzehtsiarou, K., op. cit., nota 81, y Dzehtsiarou, K. y O’Meara, N., op. cit., nota 11, p. 460.

${ }_{84}$ Véase nota 16.

85 SicilianOs, L.-A., op. cit., nota 18, p. 20. 
sis comparado pormenorizado ${ }^{86}$, sino que, dado el ámbito de nuestro estudio, nos interesan, sobre todo, aquellas características del nuevo procedimiento consultivo que han sido percibidas como sus mayores debilidades o «ángulos muertos» por ser radicalmente diferentes de lo que se ha considerado puntos fuertes del instrumento procesal ampliamente contrastado que le ha servido de modelo. Desde esta perspectiva nos ocuparemos de las dos siguientes características: a) la limitación de la legitimación a los «más altos tribunales», y b) el carácter no vinculante de las opiniones consultivas.

23. En primer lugar, mientras el art. 267 del TFUE abre la posibilidad de plantear una cuestión prejudicial ante el TJUE a cualesquiera órganos jurisdiccionales de los Estados, el art. 1 del Protocolo núm. 16 limita el acceso al nuevo procedimiento consultivo a los «más altos tribunales» de los Estados parte, aunque les deja plena libertad para designar estas jurisdicciones y para modificar esta decisión en cualquier momento ${ }^{87}$. Además, estos tribunales nacionales no vienen en ningún caso obligados a plantear una demanda de opinión consultiva ${ }^{88}$. La expresión utilizada («highest courts and tribunals», pero no «the highest») reenvía a las jurisdicciones situadas en la cima del sistema judicial nacional, pero no únicamente, como ha quedado demostrado en la práctica ${ }^{89}$.

Esta formulación restrictiva se justifica como forma de tener en cuenta las particularidades de los sistemas judiciales nacionales y con el fin de evitar la proliferación de demandas ${ }^{90}$. Podría considerarse también una reacción al «éxito» de la cuestión prejudicial, que parece en ocasiones estar

86 Véase esta comparativa, entre otros, en BENoît-RoHmER, F., "Les perspectives de réformes à long terme de la Cour européenne des droits de l'homme: "certiorari” versus renvoi préjudiciel», Revue Universelle des Droits de l'Homme, vol. 14, 2002, pp. 313-319, esp. pp. 314-316; GraGL, P., "(Judicial) Love is Not a One-Way Street: The EU Preliminary Reference Procedure as a Model for ECtHR Advisory Opinions Under Draft Protocol No. 16 (August 1, 2013)», European Law Review, 2013, núm. 2, pp. 229-247; Gerards, J., «Advisory Opinions, Preliminary Rulings and the New Protocol No. 16 to the European Convention of Human Rights. A Comparative and Critical Appraisal», Maastricht Journal of European and Comparative Law, vol. 21, 2014, núm. 4, pp. 630-651, esp. pp. 640-645, y LóPEz GUERRA, L. M., op. cit., nota 25, pp. 22-23 y 27.

87 Protocolo núm. 16 (art. 10).

88 Protocolo núm. 16 (art. 1.1) («peuvent»).

89 Aunque son 13 los Estados parte en el Protocolo núm. 16, son 14 los que han hecho esta declaración prevista por su art. 10, ya que Rumanía la hizo en el momento de la firma del Protocolo y todavía no lo ha ratificado. Todos estos Estados han designado, al menos, como jurisdicción competente para solicitar una opinión consultiva al TEDH a su Tribunal Supremo (con esta terminología o una similar). La mayoría mencionan, además, en su declaración a sus tribunales constitucionales (Albania, Andorra, Armenia, Georgia, Lituania, Rumanía y Eslovenia) u órganos jurisdiccionales de naturaleza similar (como el Consejo Constitucional francés), mientras otros se refieren a otro tipo de órganos que parecen ser las más altas jurisdicciones para una cierta categoría de asuntos. De este modo, tenemos Estados que únicamente han designado un tribunal (como Estonia, San Marino y Ucrania), otros han designado a dos (Albania, Andorra, Armenia, Georgia y Eslovenia), a tres (Francia y Lituania), a cuatro (Finlandia y Grecia), a cinco (Países Bajos) o a 17 (Rumanía). Datos disponibles en https://www.coe.int/ fr/web/conventions/full-list/-/conventions/treaty/214.

${ }^{90}$ Rapport explicatif, Protocole $n^{\circ} 16$ à la Convention de sauvegarde des Droits de l'Homme et des Libertés fondamentales, párr. 8, y PASTOR PALOMAR, N., «La entrada en vigor del Protocolo número 16 al Convenio Europeo de Derechos Humanos», Revista General de Derecho Europeo, 2019, núm. 47, p. 229. 
tornándose en «abuso» por parte de las jurisdicciones nacionales. De este modo, además, se preserva la demanda individual como forma privilegiada de acceso al sistema, acorde con la consideración del derecho de recurso individual como piedra angular del sistema. Esta «supuesta» debilidad permite además la mejor adaptación del modelo de referencia al contexto del sistema del CEDH, difícilmente transponible sin más al Consejo de Europa ${ }^{91}$. Podría incluso considerarse una de sus fortalezas de cara a la pervivencia a largo plazo del sistema del CEDH. Es una formulación coherente con la noción de agotamiento de los recursos internos ${ }^{92}$ y refleja, además, el nivel al que sería apropiado que se produzca el diálogo ${ }^{93}$, lo que vendría a reforzar el papel «constitucional» del TEDH ${ }^{94}$.

No obstante, la libertad que se da a los Estados para la designación de estas altas jurisdicciones y para su modificación podría llevarles a hacer una selección de los altos tribunales «menos activistas» o nominarlos (o cambiarlos) por razones políticas, lo que distorsionaría la naturaleza del diálogo que se quiere conseguir ${ }^{95}$. Además, existe un riesgo importante de que «el número de tribunales señalados por cada Estado haga un total exagerado de tales jurisdicciones como posibles peticionarias, lo que realmente podría asfixiar al TEDH y por tanto su función» ${ }^{96}$. Por el momento, únicamente Rumanía parece haber entonado la nota disonante, al legitimar a 17 tribunales nacionales. Bien es cierto que, siendo el segundo Estado en hacer la declaración del art. 10, su ejemplo no ha sido seguido por el resto, y además Rumanía todavía no es Parte en el Protocolo núm. 16, por lo que resultará interesante ver si confirma esta declaración en el momento de la prestación de su consentimiento en obligarse. Una posible solución hubiera sido circunscribir el número de tribunales legitimados a dos o incluso a uno ${ }^{97}$, aunque esto hubiera supuesto una importante limitación de la voluntad de los Estados. En la práctica, la mayoría de Estados han designado a su Tribunal Supremo y/o a su Tribunal Constitucional ${ }^{98}$. A nuestro juicio, si España finalmente ratificara el Protocolo núm. 16, debiera seguir este modelo. Parece la fórmula más acorde con las funciones que tienen asignadas cada uno de estos dos tribu-

91 Rapport du Groupe des Sages au Comité des Ministres, 979bis Réunion, Documents CM(2006)203, de 15 de noviembre de 2006, párr. 80.

${ }_{92}$ Rapport explicatif, Protocole $n^{\circ} 16$ à la Convention de sauvegarde des Droits de l'Homme et des Libertés fondamentales, párr. 8. Bien es cierto que no se exige que esta más alta jurisdicción tenga necesariamente que ser una de las jurisdicciones ante las que un recurso debe ser depositado para satisfacer la exigencia de agotamiento de recursos internos en el sentido del art. 35.1 del Convenio.

${ }_{93}$ Rapport explicatif, Protocole $n^{\circ} 16$ à la Convention de sauvegarde des Droits de l'Homme et des Libertés fondamentales, párr. 8. Este diálogo también se produce al más alto nivel en el ámbito europeo, ya que las opiniones consultivas son adoptadas por la Gran Sala del TEDH (art. 2.2). En este sentido, véase también Sicilianos, L.-A., op. cit., nota 18, p. 20.

94 Rapport du Groupe des Sages au Comité des Ministres, 979bis Réunion, Documents CM(2006)203, de 15 de noviembre de 2006, párr. 81 .

95 Dzehtsiarou, K. y O’Meara, N., op. cit., nota 11, pp. 462-463.

96 Hinojo Rojas, M., op. cit., nota 13, p. 691.

97 Rapport du Groupe des Sages au Comité des Ministres, 979bis Réunion, Documents CM(2006)203, de 15 de noviembre de 2006, párr. 135, e Hinojo RoJAs, M., loc. cit., nota 13, p. 692.

98 Véase nota 89. 
nales en nuestro ordenamiento y la más ajustada a la trayectoria de diálogo judicial que vienen manteniendo con el TEDH ${ }^{99}$.

Otro riesgo nada desdeñable es que "[i]t is easily conceivable, however, that national courts will use their newly acquired competence mainly to seek the authority of the ECrHR to help them solve delicate and politically sensitive issues which they would prefer not to take on themselves. [...] The authority and legitimacy of the ECrHR, however, may suffer as a result» ${ }^{100}$. En las condiciones actuales solo queda apelar a la responsabilidad tanto de los Estados al hacer y, en su caso, modificar la declaración prevista en el art. 10, como a la de los tribunales internos legitimados en el uso de este nuevo procedimiento consultivo.

24. La segunda gran diferencia respecto de la cuestión prejudicial ante el TJUE es que las opiniones consultivas no son vinculantes ${ }^{101}$. Se alegó como justificación que las opiniones consultivas intervienen en el contexto del diálogo judicial entre el Tribunal y las jurisdicciones internas ${ }^{102}$. Parece, por tanto, fundarse en un paradigma de diálogo o cooperación judicial no tan vertical o jerarquizado como el de la UE, sino más horizontal o colaborativo ${ }^{103}, \mathrm{y}$ de este modo enfrentar el «debilitado espíritu de colaboración que impregna a este [otro] procedimiento» ${ }^{104}$. Las jurisdicciones nacionales cambiarían su estatus "from opponents [...] to partners» ${ }^{105}$.

La aparente búsqueda de soluciones "colaborativas» es, además, respetuosa con el principio de subsidiariedad. Sin embargo, como esta previsión supone que la jurisdicción que formuló la demanda decide los efectos de la opinión consultiva en el procedimiento interno ${ }^{106}$, podría darse la situación de que la jurisdicción nacional no se atenga a la opinión consultiva. Esto podría cuestionar la autoridad del Tribunal en su tarea de interpretación del Convenio, constituyéndose en una importante debilidad del procedimiento.

Frente a ello se ha aducido que «la función interpretativa final y decisiva del TEDH quedaría siempre salvaguardada, por cuanto que el Tribunal sería en todo caso competente para decidir sobre las demandas individuales presentadas por cualquiera de las partes en el caso ante el tribunal nacional» ${ }^{107}$. Esta falta de obligatoriedad, por un lado, presenta la ventaja de preservar el derecho de recurso individual ante el TEDH, reforzando su función conten-

\footnotetext{
99 Véase nota 40.

100 Gerards, J., op. cit., nota 86, pp. 646-647.

101 Protocolo núm. 16 (art. 5).

102 Rapport explicatif, Protocole $n^{o} 16$ à la Convention de sauvegarde des Droits de l'Homme et des Libertés fondamentales, párr. 25.

103 Gragl, P., op. cit., nota 86, p. 22, y Voland, T. y Shiebel, B., op. cit., nota 63, p. 74.

104 Cienfuegos Mateo, M., op. cit., nota 71, p. 23.

105 Voland, T. y Shiebel, B., op. cit., nota 63, p. 79.

106 Rapport explicatif, Protocole $n^{\circ} 16$ à la Convention de sauvegarde des Droits de l'Homme et des Libertés fondamentales, párr. 25.

107 López Guerra, L. M., op. cit., nota 25, p. 28.
} 
ciosa $^{108}, \mathrm{y}$, por otro, supondría precisamente por ello «un faux-semblant» ${ }^{109}$. Además, no parece una situación muy probable, ya que, de producirse, la alta jurisdicción interna correría "le risqué d'engager la responsabilité de son État dans un contentieux futur» ${ }^{110}$. Su falta de obligatoriedad, que ha determinado la naturaleza consultiva del nuevo procedimiento, podría de este modo confirmarse como una de sus principales fortalezas.

\subsection{Un procedimiento en el marco de la función consultiva}

25. Los redactores del Protocolo núm. 16 querían que la respuesta del TEDH a la petición del juez nacional no fuera vinculante. En consecuencia, «el procedimiento que mejor encajaba, tanto desde la teoría como de la práctica del Derecho internacional, era el procedimiento consultivo que, bien es sabido, como principio general, aunque con excepciones, no obliga, al menos formalmente hablando, al órgano o entidad peticionaria a seguir lo estipulado en el dictamen judicial» ${ }^{111}$. Además, presenta la ventaja de "provide authoritative legal interpretations avoiding confrontation which is inevitable in contentious cases» ${ }^{112}$. Es decir, ante la combinación de funciones contenciosa y consultiva, que por lo demás se ha convertido en un rasgo característico de las jurisdicciones internacionales ${ }^{113}$, se optó por desarrollar la función consultiva del TEDH, lo que choca con el tradicional y característico deseo del sistema europeo de evitar toda confusión posible entre géneros y continuar privilegiando en toda circunstancia la función contenciosa ${ }^{114}$. El buen funcionamiento de la función consultiva en otras jurisdicciones internacionales, especialmente en el sistema americano de derechos humanos, parece haber contribuido a superar las reticencias y a valorarlo como modelo de referencia, aunque el objetivo en el marco del Protocolo núm. 16 no sea dar un impulso al sistema comenzando por un periodo de aprendizaje a través del método consultivo menos atentatorio contra la soberanía de los Estados ${ }^{115}$.

108 Dzehtsiarou, K. y O’Meara, N., op. cit., nota 11, p. 465.

109 SzYMCZAK, D., op. cit., nota 6, p. 103.

110 Ibid.

111 Hinojo RoJas, M., op. cit., nota 13, p. 686.

112 Dzehtsiarou, K., op. cit., nota 81.

113 Runavot, M.-C., op. cit., nota 12, p. 82. No obstante, esta autora menciona como excepción a esta regla general, el Órgano de Solución de Diferencias de la Organización Mundial del Comercio.

114 Véase supra, en especial nota 6.

115 En el sistema interamericano, durante mucho tiempo la función consultiva fue el único modo de expresión de la Corte Interamericana de Derechos Humanos (CIDH), aunque actualmente el número de sentencias supera el de opiniones. Sobre la base de este modelo, la práctica ha sido similar en la Corte Africana de Derechos Humanos y de los Pueblos. Véanse Tigroudja, H., «La fonction consultative de la Cour Interamericaine des Droits de l'Homme», en OndouA, A. y SzymczaK, D. (dirs.), La fonction consultative des juridictions internationales, París, Pedone, 2009, pp. 67-85, p. 68; MARGUENAUD, J.-P., «La fonction consultative des juridictions internationales», en ONDOUA, A. y SCYMCZAK, D. (dirs.), op. cit., nota 115, pp. 9-17, esp. p. 13; Dzehtsiarou, K. y O'MEara, N., op. cit., nota 11, pp. 449-450 y 460, y Ondoua, A., "La fonction consultative de la Cour Africaine des Droits de l'Homme et des Peuples», en Ondoua, A. y ScymczaK, D. (dirs.), op. cit., nota 15, pp. 105-116. 
26. En particular, los redactores del Protocolo núm. 16 parecen haberse fijado en el procedimiento consultivo previsto en el art. 64.2 de la Convención Americana de Derechos Humanos (o Pacto de San José) de 1969, que prevé la posibilidad de que la Corte Interamericana de Derechos Humanos (CIDH) dé una opinión consultiva al Estado miembro de la Organización de Estados Americanos (OEA) que se lo pida, acerca de la compatibilidad de una cualquiera de sus leyes internas con sus obligaciones internacionales ${ }^{116}$. No cabe duda de que no es un instrumento de reenvío judicial propiamente dicho, pero presenta dos desarrollos que parecen haber interesado al sistema europeo de cara a dotar al nuevo procedimiento consultivo de las fortalezas correspondientes.

27. En primer lugar, la CIDH ha asignado una finalidad precisa a este procedimiento consultivo del art. 64.2, a saber: ayudar a los Estados a cumplir mejor sus obligaciones internacionales ${ }^{117}$, «sin someterlos al formalismo $\mathrm{y}$ al sistema de sanciones que caracteriza el proceso contencioso» ${ }^{118}$. Una perspectiva análoga en el sistema europeo ofrece enormes ventajas de cara al fortalecimiento del nuevo procedimiento consultivo. En segundo lugar, en el sistema interamericano, si bien las opiniones consultivas tampoco están revestidas de la autoridad de cosa juzgada y no tienen, por tanto, ningún valor vinculante $^{119}$, se configuran, en cambio, como directrices para la interpretación y aplicación adecuada de los derechos humanos por los Estados que están obligados a la luz de las motivaciones que aparecen en estas opiniones. Son una constatación del derecho en vigor que participa de la «jurisprudencia» de la Corte ${ }^{120}$. No cabe ninguna duda de que este desarrollo inspiró a los redactores del Protocolo núm. $16^{121}$, con el fin de fortalecer el nuevo procedimiento ${ }^{122}$. El propio TEDH ha querido dejar claros estos extremos en su primera opinión consultiva, lo que además vendría a matizar el alcance de la falta de obligatoriedad de este tipo de opiniones ${ }^{123}$.

116 Posenato, N., «Diálogo judicial e direitos humanos - o novo Protocolo 16 à Convenção europeia dos direitos do homem», Espaço Jurídico Journal of Law, vol. 15, 2014, núm. 1, pp. 259-264, p. 261.

117 Tigroudja, H., op. cit., nota 115, p. 72.

118 Corte IDH, Restricciones a la pena de muerte (arts. 4.2 y 4.4 Convención Americana sobre Derechos Humanos), Opinión consultiva OC-3/83 del 8 de septiembre de 1983, Serie A, núm. 3, párr. 43.

119 Tigroudja, H., op. cit., nota 115, p. 81.

120 Daillier, P. y Pellet, A., Droit international public, París, LGDJ, 2002, pp. 910-911. Este efecto se aprecia también en el sistema africano. Véanse OndouA, A., op. cit., nota 115, p. 112, y QuILLEREMajzoub, F., «L'option juridictionnelle de la protection des droits de l'Homme en Afrique - Étude comparée autour de la Cour africaine des droits de l'Homme et des peuples», RTDH, 2000, núm. 44, p. 744.

121 Rapport explicatif, Protocole $n^{\circ} 16$ à la Convention de sauvegarde des Droits de l'Homme et des Libertés fondamentales, párr. 27.

122 Bien es cierto que en el ámbito interamericano este desarrollo responde a una motivación diferente. La CIDH atenúa la frontera entre el procedimiento contencioso y el consultivo para pronunciarse sobre litigios que no le llegarían jamás por la vía contenciosa dado que no se trata de un sistema continental como el europeo (al quedar fuera los Estados Unidos de América y Canadá) (TigroudJA, H., op. cit., nota 115 , p. 76).

${ }_{123}$ Así, en su primera opinión consultiva (véase nota 16), el TEDH ha afirmado que: «La Cour n'est compétente ni pour se livrer à une analyse des faits, ni pour apprécier le bien-fondé des points de vue des parties relativement à l'interprétation du droit interne à la lumière du droit de la Convention, ni pour se prononcer sur l'issue de la procédure. Son rôle se limite à rendre un avis en rapport avec les questions qui lui ont été soumises. C'est à la juridiction dont émane la demande qu'il revient de résoudre les questions 
28. Esta atenuación de la frontera entre el procedimiento consultivo y el contencioso parece haber facilitado que el nuevo procedimiento previsto por el Protocolo núm. 16 presente además algunos elementos que se toman de la función contenciosa del TEDH, y muy especialmente del procedimiento de remisión a la Gran Sala ${ }^{124}$. El mimetismo con el procedimiento del art. 43 del CEDH es evidente por lo que se refiere al examen de la admisibilidad por un colegio de cinco jueces de la Gran Sala previa y separadamente al examen del fondo ${ }^{125}$, a la competencia de la Gran Sala para emitir una opinión consultiva $^{126}$, en materia de integración del juez elegido a título del Estado parte correspondiente en la Gran Sala ${ }^{127}$, y respecto de la participación procesal de terceros $^{128}$.

29. Estas previsiones parecen obedecer a la voluntad de profundizar en el rol «constitucional» del TEDH. Tales paralelismos contribuirían a equiparar la autoridad de las opiniones consultivas a la de las sentencias de la Gran Sala. Igualmente podría valorarse como fortaleza la configuración de la intervención de terceros (en particular, del Comisario para los Derechos Humanos, como máximo mecanismo no convencional de protección de los derechos humanos en el Consejo de Europa), ya que la construcción de una respuesta de manera «colaborativa» ayudaría a su mayor aceptación y a su efecto de cosa interpretada erga omnes, reforzando su autoridad jurisprudencial y su papel constitucional. No obstante, también plantean algunos problemas que pueden tornarse en debilidades. Aunque entendible para enfrentar los recelos de los Estados, no parece, sin embargo, muy acertada a priori la incorporación del juez a título del Estado parte correspondiente. No obstante, como apunta algún autor, esta presencia quedaría neutralizada por el principio de independencia de los jueces ${ }^{129}$.

30. También se han valorado negativamente los efectos que sobre la carga de trabajo del TEDH tendría la obligación que se le impone de jus-

que soulève l'affaire et de tirer, selon le cas, toutes les conséquences qui découlent de l'avis donné par la Cour pour les dispositions du droit interne invoquées dans l'affaire et pour l'issue de l'affaire» (párr. 25). Ahondando en esta idea, ha añadido que: «Son rôle n'est pas de statuer contradictoirement sur des requêtes contentieuses par un arrêt ayant force obligatoire mais, dans un délai aussi rapide que possible, de fournir à la juridiction qui a procédé à la demande une orientation lui permettant de garantir le respect des droits de la Convention lorsqu'elle jugera le litige en instance» (párr. 34).

${ }^{124}$ Rapport explicatif, Protocole $n^{\circ} 16$ à la Convention de sauvegarde des Droits de l'Homme et des Libertés fondamentales, párrs. 9, 14-15 y 18-19.

125 Protocolo núm. 16 (art. 2.1), y Rapport explicatif, Protocole $n^{\circ} 16$ à la Convention de sauvegarde des Droits de l'Homme et des Libertés fondamentales, párr. 14.

126 Protocolo núm. 16 (art. 2.2).

127 Protocolo núm. 16 (art. 2.3), y Rapport explicatif, Protocole $n^{\circ} 16$ à la Convention de sauvegarde des Droits de l'Homme et des Libertés fondamentales, párr. 18.

128 Protocolo núm. 16 (art. 3), y Rapport explicatif, Protocole $n^{\circ} 16$ à la Convention de sauvegarde des Droits de l'Homme et des Libertés fondamentales, párrs. 19-20. Además, el Reglamento del TEDH dispone expresamente que las previsiones para terceros intervinientes «se aplicarán mutatis mutandis» al nuevo procedimiento consultivo: véase Cour EDH, Règlement de la Cour, Amendements au Règlement de la Cour adoptés par la Cour plénière le 19 septembre 2016 (articles 1, 24, 29, 34, 44 et 82, nouveau chapitre $X$ ), en vigor desde el 1 de agosto de 2018 (art. 44.7).

129 RunAVOT, M.-C., op. cit., nota 12, p. 91. 
tificar cada inadmisión, que no existe en el proceso de remisión a la Gran Sala ${ }^{130}$. Bien es cierto que el propio TEDH acabó considerando que podría ser útil ofrecer una motivación, al contribuir al objetivo de crear un diálogo constructivo con los tribunales nacionales, advirtiendo, no obstante, que tales motivaciones normalmente no serán muy extensas ${ }^{131}$. En todo caso, se ha aconsejado que el Tribunal haga uso de este poder de rechazar demandas con moderación, rechazando aquellas solicitudes únicamente cuando concurren «razones decisivas» siguiendo una práctica similar a la mantenida por el Tribunal Internacional de Justicia de las Naciones Unidas ${ }^{132}$. Esto parece sugerir el Informe explicativo del Protocolo núm. 16 al disponer que "[l]a Cour dispose d'un pouvoir discrétionnaire pour accepter ou non une demande, même si l'on peut s'attendre à ce que la Cour hésite à refuser une demande» ${ }^{133}$.

31. Por otro lado, se ha dicho que la intervención de terceros no va a facilitar que la respuesta del TEDH sea pronta y rápida ${ }^{134}$, además de constituirse como un medio adicional con el que cuentan los Estados para "garder une maîtrise sur la mise en ouvre de cette nouvelle compétence» ${ }^{135}$. Frente a esto último, podría alegarse que la intervención del Comisario para los Derechos Humanos en el procedimiento contencioso ha sido poco habitual (aunque siempre en asuntos verdaderamente importantes) ${ }^{136}$ y que la participación de terceros en la cuestión prejudicial ante el TJUE está formulada en términos más amplios ${ }^{137}$. La práctica en el marco de la primera opinión consultiva aporta datos a tener en cuenta: la intervención de terceros fue amplia aunque no participara el Comisario para los Derechos Humanos ${ }^{138}$ y el Tribunal dictó su opinión en menos de seis meses desde la recepción de la petición (por otro lado, lejos de los quince o dieciséis meses de media que tarda el TJUE en resolver las cuestiones prejudiciales) ${ }^{139}$.

130 Cour EDH, Reflection paper on the proposal to extend the Court advisory opinion, ref. 3853038.

131 Cour EDH, Opinion of the Court on the Draft Protocol $n^{\circ} 16$ to the Convention extending its competence to give advisory opinions on the interpretation of the Convention, de 6 de mayo de 2013.

132 Sicilianos, L.-A., op. cit., nota 18, p. 21.

133 Rapport explicatif, Protocole $n^{\circ} 16$ à la Convention de sauvegarde des Droits de l'Homme et des Libertés fondamentales, párr. 14.

134 Hinojo RoJAs, M., op. cit., nota 13, p. 698.

135 Runavot, M.-C., op. cit., nota 12, p. 91.

136 SiCILIANOS, L.-A., op. cit., nota 18, p. 23.

137 Véase el art. 267 del TFUE.

138 Véase nota 16. Aunque el comisario no hizo uso de su derecho (párr. 5), presentaron observaciones escritas el Gobierno francés (párr. 5), pero también se recibieron "des gouvernements britannique, tchèque et irlandais, du Défenseur des droits, du centre d'études interdisciplinaires du genre du département de sociologie et de la recherche sociale de l'Université de Trente, ainsi que des organisations non gouvernementales AIRE Centre, Helsinki Foundation for Human Rights, ADF International, Coalition internationale pour l'abolition de la maternité de substitution, et Association des médecins catholiques de Bucarest, que le président avait autorisés à intervenir (article 3 du Protocole $n^{\circ}$ 16)» (párr. 6).

139 Véase nota 16, y TJUE, Rapport Annuel 2018. Activité judiciaire, 2019, p. 138 (disponible en curia.europa.eu). 


\section{CONCLUSIONES}

32. El nuevo procedimiento consultivo ante el TEDH ejemplifica la gran «capacidad creativa» que se está desplegando en el marco del proceso de reforma del sistema de protección del CEDH en aras a garantizar su pervivencia a largo plazo. Su gran atractivo radica en que se trata de un mecanismo peculiar y completamente original, que combina rasgos prejudiciales, consultivos y contenciosos.

33. Una de sus principales fortalezas es precisamente el hecho de aunar algunos de los elementos probados como ventajosos en cada uno de los modelos que le han servido de referencia como modo de garantizar una fórmula de éxito, adaptada a los objetivos que se pretenden y al contexto en el que se enmarca, pero también como forma de reaccionar en un estadio precoz frente a las reticencias y problemas que pudieran suscitarse. La voluntad de instaurar un procedimiento de diálogo judicial entre iguales dotado de elementos idóneos para el fortalecimiento de la autoridad y del papel constitucional del TEDH pueden también valorarse como fortalezas.

34. La oportunidad que supone el «Proceso de Interlaken» y la nueva concepción del principio de subsidiariedad son además un excelente caldo de cultivo para que este nuevo procedimiento desarrolle todas sus potencialidades.

35. Pero al mismo tiempo este contexto no está exento de importantes amenazas. La más importante se traduce precisamente en las reticencias de algunos Estados a estos desarrollos, consagradas incluso a nivel convencional a través del Protocolo núm. 15, que puede considerarse la antítesis del Protocolo núm. 16.

36. Tampoco debe menospreciarse el efecto debilitante que puedan llegar a tener algunas de sus características intrínsecas. Así, las cuestiones de orden lingüístico, la posibilidad de plantear una demanda individual respecto del mismo asunto o la limitada capacidad de trabajo de la Gran Sala podrían incidir negativamente en la carga de trabajo del Tribunal. Además, la configuración del Protocolo núm. 16 como facultativo, la discrecionalidad de los Estados a la hora de realizar y modificar la declaración de su art. 10 o la incorporación del juez a título del Estado parte correspondiente podrían facilitar un cierto control de los Estados sobre su implementación. Incluso algunas de las características del procedimiento consultivo que contribuirían a reforzar el papel constitucional del TEDH podrían menoscabar su rol principal de garante de derechos individuales.

37. La gran incógnita de esta ecuación sigue siendo conocer el número de Estados que ratificarán el Protocolo núm. 16 y las condiciones en que lo harán, y averiguar el uso que de este nuevo procedimiento consultivo efectivamente realizarán los órganos jurisdiccionales internos habilitados.

38. Resulta, por tanto, necesario permanecer vigilantes y hacer un seguimiento de la implementación de este procedimiento consultivo para valorar su impacto en el futuro del sistema con el fin de adoptar, en su caso, las me- 
didas correctivas necesarias —en especial, en defensa del derecho de recurso individual ante el TEDH - , todo ello de cara a una mayor eficacia del sistema, que supone al fin y al cabo una mayor protección de los derechos humanos en el marco del CEDH.

\section{RESUMEN}

\section{EL POTENCIAL DESARROLLO DEL NUEVO PROCEDIMIENTO CONSULTIVO ANTE EL TRIBUNAL EUROPEO DE DERECHOS HUMANOS: FORTALEZAS, DEBILIDADES, OPORTUNIDADES Y AMENAZAS}

El Protocolo núm. 16 del Convenio Europeo de Derechos Humanos, que entró en vigor el 1 de agosto de 2018 respecto de los Estados que lo han ratificado, establece la posibilidad para las altas jurisdicciones nacionales de los Estados parte en el mismo de solicitar opiniones consultivas al TEDH sobre cuestiones de principio relativas a la interpretación o a la aplicación de los derechos y libertades definidos por el CEDH o sus Protocolos. Ante los desarrollos recientes, nos hemos planteado valorar el particular potencial que tiene este nuevo procedimiento consultivo para garantizar la pervivencia del sistema europeo de protección de derechos humanos a futuro. Para ello, se ha procedido al examen de su contexto, que no es otro que el proceso de reforma del sistema del CEDH, y de sus elementos más significativos en tanto que procedimiento consultivo de reenvío judicial. Como resultado de este análisis se han identificado las fortalezas y oportunidades con las que cuenta para la consecución de sus objetivos, así como las debilidades y amenazas que acechan y que pueden incidir negativamente en la eficacia del sistema a largo plazo, lo que exige permanecer vigilantes para, en su caso, adoptar medidas correctivas apropiadas.

Palabras clave: Convenio Europeo de Derechos Humanos, Protocolo núm. 16, Tribunal Europeo de Derechos Humanos, proceso de reforma del TEDH, principio de subsidiariedad, derecho a un recurso individual, diálogo judicial, cuestión prejudicial, opinión consultiva.

\section{ABSTRACT \\ THE POTENTIAL DEVELOPMENT OF THE NEW ADVISORY PROCEDURE BEFORE THE EUROPEAN COURT OF HUMAN RIGHTS: STRENGTHS, WEAKNESSES, OPPORTUNITIES AND THREATS}

Protocol No. 16 to the European Convention on Human Rights, which came into force on 1 August 2018 for the States that have ratified it, allows the highest courts and tribunals of a State Party to request the ECtHR to give advisory opinions on questions of principle relating to the interpretation or application of the rights and freedoms defined in the Convention or the protocols. Due to recent developments, we have assessed the particular potential of this new advisory procedure to guarantee the long-term effectiveness of the Convention system. For that purpose, we have examined its context, which covers the reform process of the ECHR system, and its most significant elements as an advisory procedure promoting judicial dialogue. As a result of this analysis, we have identified some strengths and opportunities that may ensure the achievement of its objectives, as well as weaknesses and threats which may adversely affect the long-term effectiveness of the system. The latter may require to take, if necessary, appropriate corrective measures.

Keywords: European Convention on Human Rights, Protocol No. 16, European Court of Human Rights, ECtHR reform process, principle of subsidiarity, access to justice, jurisdictional dialogue, preliminary reference, advisory opinion. 